\title{
Sobre as bases dos procedimentos investigativos em psicanálise
}

\author{
Anna Carolina Lo Bianco ${ }^{1}$
}

\begin{abstract}
Resumo
O presente trabalho examina as bases da pesquisa psicanalítica. Parte das marcas deixadas nas investigações psicanalíticas pelos procedimentos científicos de disciplinas como a neurologia e a neurofisiologia no século XIX. Em seguida, acompanha o surgimento de um novo objeto, o sujeito do inconsciente, o qual, ainda que requeira operações que mantenham o rigor e a precisão característicos do pensamento científico, implica formas de investigação mais apropriadas ao campo recém-constituído. Por fim, conclui que, ao contrário de emular os procedimentos das ciências naturais, a pesquisa em psicanálise tem de reconhecer a especificidade de seu objeto, pois este só se deixa circunscrever em análise, na qual analista e analisante estão implicados nas próprias produções inconscientes sob investigação. Essa é a particularidade da nova forma de saber que marca de modo indelével o pensamento do século XX em diante.

Palavras-Chave: Psicanálise; Pesquisa; Inconsciente; História da psicanálise; Pensamento científico.
\end{abstract}

\section{On the basis of investigation procedures in psychoanalysis}

\begin{abstract}
The work examines the basis of psychoanalytical research. It begins by examining the influence of scientific procedures, used by neurology and neurophysiology in the nineteenth century, on psychoanalysis. It then observes the discovery of a new subject matter of research - the unconscious. The latter following the rules of rigorous and precise scientific thought still implies the need for new, adequate forms of investigation for the recently forged field of research. As a conclusion it states that rather than imitating the natural sciences procedures, psychoanalytical research needs to recognise the specificity of its subject matter. Such subject matter can only be apprehended during the analytic session, where analyst and analysand are involved in the very unconscious productions under investigation. This constitutes the particular, new kind of knowledge that so much has influenced the twentieth century thought and beyond.

Keywords: Psychoanalysis; Research; Unconscious; History of psychoanalysis; Scientific thought.
\end{abstract}

No presente artigo, procuraremos refletir sobre as questões da pesquisa psicanalítica na atualidade. Partiremos das características que tomam as investigações psicanalíticas no século XIX, no qual encontra suas raízes, para em seguida acompanhar como o surgimento de um novo objeto, o sujeito do inconsciente, impôs formas de investigação mais apropriadas ao campo recém-constituído. Trata-se de um campo cuja especificidade mais marcante é ter sua dimensão escrita acrescentada ao momento em que a experiência analítica se dá, momento da clínica, da presença do analista perante o analisante.

O objetivo do nosso trabalho é apontar para o fato de que, como não poderia deixar de ser, a pesquisa que se realiza atualmente traz a marca de seu desenvolvimento histórico e se estabelece ao reconhecer a especificidade de sua área de atuação. Ao mesmo tempo, busca manter os padrões de rigor válidos para todas as pesquisas científicas.

A preocupação com a especificidade do objeto da psicanálise faz parte de uma minoria dos artigos que lidam com esse tema, em geral brasileiros. Da mesma

Endereço para correspondência:

${ }^{1}$ E-mail: teoriapsi@ufrj.br maneira, dificilmente encontramos autores que procurem situar a relação psicanálise/pesquisa vis-à-vis a constituição histórica da psicanálise, como procuraremos fazer. Tomando de início os desenvolvimentos angloamericanos, o que encontramos são textos, em sua maioria enunciados sob uma ótica, que, como reconhece Wallerstein (2001), privilegia a tradição intelectual de um "empirismo pragmático" (p. 294) cientificista. Podemos distinguir, para os propósitos de nossa apresentação, dois grupos principais que organizam os incontáveis artigos que já se acumulam nessa área. O primeiro deles privilegia o estudo dos resultados e da eficácia do que chamam de psicoterapias psicanalíticas (Bachrach, Galatzer-Levy, Skolnikoff \& Waldron, 1991; Fonagy \& Target, 1994; Fonagy \& Target 1996; Kantrowitz, Katz, Greenman, Humphrey, Paolitto, Sashin \& Solomon, 1989; Oremland, Blacker \& Norman, 1975; Safran \& Aron, 2001; Strupp, Schacht \& Henry, 1988; Target \& Fonagy, 1994a; Target \& Fonagy, 1994b; Wallerstein, 2003; Weber, Bachrach \& Solomon, 1985a; Weber, Bachrach \& Solomon, 1985b). Tais estudos são encontrados não apenas em 
publicações mais recentes, como as citadas, mas também desde os primórdios da pesquisa em psicanálise. Em seu levantamento, Wallerstein (2001) mapeia quatro gerações de pesquisadores americanos que desde 1917 se voltam para a questão dos resultados e da eficácia da terapia psicanalítica. Não podemos deixar de observar que a orientação pragmática e empírica de tais autores certamente é responsável pelo fato de que seus trabalhos remetam antes a pesquisas voltadas para a satisfação de consumidores, para um optimum na relação custo-benefício, que a reflexões que se dirijam a sujeitos do inconsciente.

O segundo grupo toma como questão a querela da cientificidade da psicanálise. Em relação a esse tópico, vemos muitas vezes os autores perseguindo um caminho que, como pretendemos mostrar adiante, é contrário ao que Freud teria percorrido. Enquanto o inventor da psicanálise se afastou progressivamente de um entendimento positivo acerca do sujeito, o que encontramos é a introdução forçada de procedimentos que garantam o referido entendimento. Trata-se, para esses autores, de permitir à psicanálise uma constante atualização e um alinhamento mais estrito com o conhecimento permitido pela ciência empírica existente (Schachter, 2002). É com esse objetivo que, em 1989, cria-se nos EUA uma Sociedade para o Avanço da Pesquisa Quantitativa (SAQRP) (Psychoanalytic Psychology, 1989). Essa sociedade vem responder à crescente preocupação dos pesquisadores com a falta de verificação empírica que acreditam rondar a psicanálise (ver a esse respeito os comentários de Holt, 1985).

Os pesquisadores que não adotam um método quantitativo em suas investigações ainda assim tratam quase sempre de demonstrar e defender ou atacar o pertencer da psicanálise ao reino da ciência. Vale dizer, têm como horizonte de discussão a preocupação de julgar a cientificidade da psicanálise. A polêmica gerada por um artigo já não tão recente (Shevrin, 1995a), que procura saber se a psicanálise é uma ciência, duas ciências ou não é ciência, ilustra exemplarmente a constante preocupação com o estatuto científico da psicanálise. Shevrin (1995b), em resposta às reações a seu artigo, reafirma a necessidade da pesquisa sobre a efetividade da psicoterapia e a adoção do método clínico ao lado da investigação experimental, para assim garantir a cientificidade da psicanálise. Mesmo os autores que abrem um debate (Irwin, 1996) ou se referem à discussão (Nash, 1990) entre a busca de sentido e o intencionalismo que caracterizam a hermenêutica em oposição à possibilidade de verificação empírica de dados observáveis estão constantemente confrontados com a questão da cientificidade dos achados e procedimentos analíticos. Encontramos, sobretudo na literatura angloamericana, um movimento que oscila entre a defesa da psicanálise como uma ciência igual a qualquer outra (Cremerius, 1999; Gedo, 2001), cujas proposições podem ser testadas empiricamente (Holt, 2002), e ataques como os de Crews (1986 e 1995), que afirma que a psicanálise não pode se tornar uma ciência.

A dúvida acerca de se a psicanálise é ou não um conhecimento científico data certamente da época de Freud (1900/1996). Seu livro sobre a interpretação dos sonhos encontrou forte resistência por parte dos cientistas da época, que o consideravam mais apropriado a um conto de fadas (Strachey, 1975). Críticas às vezes muito semelhantes vêm sendo feitas ao longo do século. Um autor cuja crítica marcou o cenário dessas discussões foi Ellenberger (1970), que afirmou que o estatuto científico da psicanálise não estava esclarecido e que dificilmente suas descobertas seriam incorporadas pela ciência. Mais de duas décadas depois, a posição desse autor ainda serve de apoio para artigos como o de Dumont (1994), o qual critica as asserções de Magnavita (1993) de que a descoberta freudiana se prestava à investigação científica de certas desordens, bem como das técnicas de tratamento para combatê-las.

O livro de Ellenberger foi traduzido para o francês (Ellenberger, 1994), e encontramos na cena européia uma divulgação acentuada de suas idéias. A transferência do que consideramos a querela da cientificidade para outro contexto cultural naturalmente faz com que ela se apresente com novas inflexões. Nesse ponto, não se tem mais os incontáveis estudos sobre a eficácia e a utilidade da psicanálise. Mesmo assim, deparamo-nos, no contexto francês, com a tentativa de estabelecer o estatuto científico da psicanálise. Laplanche (1966) reconhece não ser simples a questão de saber se a psicanálise é uma ciência e de defini-la em face dos critérios de uma pesquisa científica. Chega a mostrar, no entanto, como o tratamento psicanalítico apresenta uma situação quase-experimental passível de verificação a cada vez, e afirma que o relato de tal tratamento, ao permitir a descrição da estrutura psíquica de um sujeito, fornece o "exemplo de uma elaboração 'exata' no domínio das ciências humanas" (p. 149). O trabalho de Legrand (1973) contrapõe à ciência empírica, referida aos neopositivistas vienenses e a Popper (1968), uma definição teoricista de ciência que a identifica com a produção de um sistema de conceitos teóricos irredutíveis a qualquer apreensão empírica (Althusser, 1965). Indicando dificuldades em ambas as vias, propõe à psicanálise uma terceira. A situação analítica funcionaria como mediadora que estrutura os dados empíricos e os prepara para uma interpretação guiada por uma teoria de referência já constituída, criando assim um novo conhecimento. Ainda que deslocada da referência ao empirismo anglosaxão, mesmo assim, encontramos nas proposições mencionadas a defesa da cientificidade da psicanálise. 
É em um cenário em grande parte herdado das discussões francesas que podemos encontrar um número crescente de estudos sobre a pesquisa psicanalítica em nosso país. Tais estudos começam a surgir com mais freqüência a partir do início dos anos 1990, época em que a psicanálise começa a se firmar como disciplina nos cursos brasileiros de pósgraduação. Ainda que não abandonem por completo a querela da cientificidade, não a situam em referência ao empirismo e ao pragmatismo que caracterizam os estudos norte-americanos, dirigindo-se de preferência às questões do rigor e da precisão das conceituações teóricas e quase sempre deixando entrever a especificidade do objeto da psicanálise.

Mezan (1990) toma dois termos da definição de Laplanche \& Pontalis (1967) - ficção e elaboração -, que a seu ver remetem respectivamente à escuta da imaginação do paciente e à elaboração e construção de modelos conceituais. Com base neles, concebe a possibilidade de construção de uma teoria de acordo com os modelos universais do funcionamento psíquico desenvolvidos por Freud. Birman (1993) busca dar orientação metodológica à questão da relação psicanálise/pesquisa e mostra como Freud ultrapassa os padrões científicos que vigoravam para as ciências naturais ao representar teoricamente o que considera uma nova modalidade de cientificidade para a psicanálise. Garcia-Roza (1993) faz uma distinção entre pesquisa clínica e pesquisa acadêmica em psicanálise. A última teria como objetivo o trabalho teórico que visa verificar a validade formal da teoria. No entanto, longe de ter apenas esse objetivo, contrastando-a com o trabalho do epistemólogo, o autor afirma que a pesquisa acadêmica em psicanálise deve se dedicar também à "releitura" da teoria. Com essa noção aponta para a introdução do novo na referida teoria, por meio da multiplicação das possibilidades de sentido retiradas da clínica psicanalítica.

Lino da Silva (1993) reconhece o "objeto esquivo" da psicanálise (p. 21) e considera que, na pesquisa como na clínica, deve-se esperar a emergência de novos significados, os quais seriam articulados em uma teoria que conferiria à psicanálise seu estatuto de cientificidade. Mezan (1993) procura saber o que significa a pesquisa em psicanálise. Também se referindo ao inconsciente, deriva da especificidade desse objeto as possibilidades de teorização em psicanálise. Em suas reflexões sobre o uso do material clínico na pesquisa psicanalítica, Safra (1993) afirma que a maneira de garantir a objetividade dessa pesquisa está no controle exercido sobre a análise do próprio analista.

Gondar (1995) sustenta que Freud, ao romper com a concepção tradicional de clínica, inaugura uma clínica de investigação, isto é, um espaço em que tratamento e cura são resultantes de procedimentos de investigação. Machado Pinto (1999) identifica a presença da transferência na base do processo de criação, mesmo na atividade científica. Ao analista caberia a demonstração da passagem da crença no saber da ciência, implicada na transferência, para a evidência de uma ciência do singular. Uma discussão com as ciências empíricas é estabelecida por Palombini (1999), que igualmente reconhece um estatuto de conhecimento próprio à psicanálise. A mesma especificidade é defendida por Nobre (1999), que defende o fato de que a pesquisa em psicanálise não pode ser motivada pela vontade de saber e buscar dados exatos para a comprovação de hipóteses formuladas $a$ priori, argumentando que a direção tomada por essa pesquisa é dada pela experiência que afeta o pesquisador ou pela qual ele se deixa afetar.

Procurando se deslocar dos confrontos diretos entre a psicanálise e a ciência cartesiana experimental, positivista ou neopositivista, Beividas (1999a) os reencontra ao se alinhar com essas ciências para interrogar o que considera um excesso transferencial e uma acentuada submissão às autoridades de Freud e Lacan na pesquisa psicanalítica. Seu trabalho foi contestado por Elia (1999), que argumenta que a psicanálise não constitui um saber a mais entre outros que compõem as ciências da natureza ou da cultura. Segundo esse autor, ela encontra sua chance de produzir uma pesquisa frutífera e conseqüente justamente no reconhecimento de uma transferência simbólica, que a singulariza. Beividas (1999b) discorda de Elia quando este afirma que a psicanálise não integra o campo científico, afirma que ela é uma ciência humana e reafirma que os excessos transferenciais devem ser combatidos para que ela faça parte do referido campo.

Usando o conceito de tipo ideal de Weber (1949), não seria exagero reconhecer, por um lado, uma típica produção norte-americana ou anglo-saxã que, conforme afirmamos, nutre-se do empirismo pragmático, e, por outro, uma produção nacional também típica, que, na última década, se dirige à questão da pesquisa psicanalítica. Inseridos nesse contexto, desenvolveremos nosso argumento, centrando-o, diferentemente dos aqui apresentados, na história do percurso freudiano. Veremos se constituírem aí as bases para pensar os procedimentos investigativos em psicanálise.

\section{As raízes dos procedimentos investigativos em psicanálise}

A educação formal de Freud se dá em estreito contato com as pesquisas acadêmico-científicas de fins do século XIX. Ainda na escola de medicina, Freud se dedicava especialmente aos estudos de fisiologia, 
biologia e zoologia, recebendo, logo após o segundo ano, uma bolsa em zoologia para pesquisar a estrutura gonádica das enguias. Certamente essa pesquisa, feita sob a orientação de Carl Claus, profissional de "excelente reputação como cientista" (Jones, 1980, p. 43), exigiu do estudante grande familiaridade com procedimentos investigativos cientificamente controlados de acordo com os cânones da época. Freud dissecou e examinou ao microscópio centenas de enguias; o artigo resultante dessas investigações foi lido na Academia de Ciências de Viena e, posteriormente, publicado em seu Boletim (Jones, 1980). Ainda que o jovem não tenha ficado satisfeito com o trabalho, por achá-lo pouco original, o episódio serve como ilustração do tipo de formação na qual o futuro inventor da psicanálise estava envolvido (Jones, 1980; Gay, 1989). Acreditamos estarem sendo lançadas aí as bases de um contato com o pensamento científico, que deixará marcas extremamente sensíveis na psicanálise, mesmo sabendo que ela não importa diretamente as operações prescritas por tal pensamento.

Freud prossegue sua pesquisa no Laboratório de Fisiologia da Universidade de Viena, dirigido por um professor "positivista por temperamento e convicção" (Gay, 1989, p. 48), cujas aulas são seguidas com muito afinco pelo interessado discípulo. Ele se chamava Ernst Brücke e fazia parte da Escola Médica de Helmholtz, um amplo movimento científico cuja história da participação no desenvolvimento da fisiologia no final do século XIX foi altamente considerada por suas contribuições ao desenvolvimento dessa disciplina. Uma das características importantes desse movimento é retratada pelo juramento feito por seus integrantes, segundo o qual afirmavam que "nenhuma outra força, que não as físico-químicas, estaria ativa no organismo" (cf. Jones, 1980; Berchérie, 1983, p. 146). Tratava-se de um grupo que, baseado em um consenso fisicalista, sistematicamente interpretava os fenômenos orgânicos em termos de força, quantidade e movimento de moléculas. Freud passou alguns anos nesse laboratório e nele teve um papel de relativa importância, dando marcantes contribuições para os estudos que lá se faziam, como quando, por exemplo, divisou uma interessante técnica de pesquisa em histologia e desenvolveu inúmeros trabalhos originais sobre a teoria do neurônio, que então se constituía.

Esses trabalhos são contemporâneos aos do médico Fechner, cujas teorias foram muito úteis a Freud, que recorreu a elas mesmo em textos tardios como "Mais além do princípio do Prazer" (1920/1996). O objetivo de Fechner era construir uma ciência fundada sobre a experimentação e sobre a medida, determinando as leis que ligam os "fenômenos físicos (psicofísica externa) e fisiológicos (psicofísica interna) aos fenômenos mentais, no sentido de uma relação regular e quantificável" (Bercherie, 1983, p. 144). Ele introduziu duas inovações conceituais importantes para o pensamento científico da época, em geral, e para a emergente disciplina psicológica, em particular. A primeira se constituiu na fonte da psicologia experimental moderna, sendo responsável pelos primeiros métodos de experimentação; a segunda foi a via por meio da qual se introduziu um "materialismo mecânico rigoroso em psicologia" (Berchérie, 1983, p. 145) e se tornou possível quando o autor supôs que os fatos psíquicos seriam da mesma natureza que os físicos, podendo se exprimir em linguagem semelhante: a linguagem da quantidade, da medida e das leis matemáticas. Da mesma maneira que na fisiologia do sistema nervoso, já estabelecida pela Escola de Helmholtz, na psicologia as noções de força e de uma energia nervosa circulante são tomadas como dado corrente, certamente presente nas concepções freudianas desde o princípio de suas formulações sobre o aparato psíquico, em 1895. Ainda, as concepções de prazer e desprazer utilizadas por Freud são exemplos de mecanismos psíquicos concebidos por Fechner, que os aproximava das leis de equilíbrio sistêmico em física.

Não necessitamos nos prender aos detalhes das proposições desses vários autores, que, de certa forma, precederam Freud, servindo-lhe de guias para suas futuras teorias. Basta-nos mostrar o contexto que o cercava e do qual participava, tanto por sua formação quanto por sua opção de trabalho, já depois de formado, junto a esses mestres que representavam de forma fidedigna o pensamento científico da época.

Reconhecido e acolhido em um lugar genuinamente conquistado por seu esforço e por sua capacidade, a pergunta que naturalmente se coloca é: "Por que Freud não passa a ocupá-lo e segue a promissora carreira de pesquisador que se abria à sua passagem?". Lacan (1975), em um fino comentário, diz que se ele não o ocupa, é porque tinha lá suas razões. Refere-se então à ousadia de Freud. Uma ousadia que o faz retirar-se das questões legítimas que eram colocadas por um mundo legítimo - acadêmico-científico de finais de século - e se debruçar sobre o que de importante se passava com ele, "suas antinomias de infância, seus problemas neuróticos, seus sonhos". Passa a se dedicar às contingências da vida cotidiana: "a morte, a mulher, o pai” (Lacan, 1975, p. 8).

\section{Um novo objeto requer novo entendimento sobre a pesquisa}

Freud, ao deixar o Laboratório de Fisiologia, passa praticamente mais dez anos se dedicando às mais variadas formas de clínica. Começando pela enfermaria de medicina interna, trabalhou em psiquiatria, 
dermatologia, oftalmologia e otologia, sempre interessado nas incidências neurológicas das várias afecções estudadas. $\mathrm{Na}$ enfermaria de dermatologia, por exemplo, procurava estudar os pacientes da seção de sífilis em razão de sua conexão com as patologias do sistema nervoso. Ao mesmo tempo, tomava parte em um grande número de pesquisas, principalmente sobre o sistema nervoso central, em particular sobre a medula, tendo recebido um título de certa importância na docência de neuropatologia.

Essa época de estágio no hospital geral culminou com sua ida a Paris para trabalhar com Charcot, onde esteve exclusivamente devotado à neurologia Jones, 1980). Ao voltar, retoma as pesquisas de neurologia, mas, fortemente marcado pelo método clínico do mestre francês, pouco a pouco se desliga dos "aspectos mais mecânicos" da Escola de Helmholtz e se volta para a distinção entre dados psicológicos e fisiológicos (Jones, 1980, p. 236). É quando escreve seu estudo sobre a afasia (Freud, 1891/1987), no qual faz críticas às várias teorias sobre o funcionamento do cérebro, mais especialmente a seu antigo mestre Meynert, e demonstra que a doutrina que considerava o córtex cerebral uma "projeção" das várias partes do corpo estava baseada em erros de histologia anatômica. Caso houvesse projeção, Freud conclui, esta se daria em termos funcionais, e não topográficos.

Ao mesmo tempo, e não sem certa surpresa, podemos constatar que a defesa de um ponto de vista psicológico está presente também na crítica feita ao próprio Charcot (Freud, 1893/1996b). Nela, Freud mostra que o approach "exclusivamente nosográfico adotado pela Escola de Salpêtrière não era adequado para o objeto puramente psicológico" (p. 22). Vemos aí Freud se dirigindo a um objeto diferente do que vinha até então sendo visado, seja por seus mestres anteriores, ligados às ciências médicas, seja pelo próprio Charcot, que já mantinha, em relação àqueles, posição bastante afastada.

Charcot havia tido um papel muito importante ao reconhecer na histeria um quadro clínico com contornos próprios, que mereceriam atenção não só do médico, mas também dos teóricos de medicina. Como é sabido, até então a histeria era vista com descrédito; não só a histeria como aqueles que se empenhavam em seu tratamento. Charcot foi quem trouxe à cena a objetividade e a qualidade genuína do fenômeno histérico, um fenômeno que ultrapassava o conhecimento consciente imediato do paciente:

Se uma pessoa sadia fosse interrogada, estaria em posição de dizer que impressão a estava atormentando; mas a histérica responderia que não sabe. Levantar-se-ia de imediato a pergunta de como um paciente histérico pode ser tomado por um afeto de cuja causa ele afirma nada conbecer. Se mantivermos nossa conclusão de que um processo psíquico correspondente tem de estar presente, e se ainda assim acreditamos no paciente quando ele o nega; se juntamos as várias indicações de que o paciente está se comportando como se soubesse dele; e se entramos na vida do paciente e encontramos alguma ocasião, algum trauma, que evoca precisamente essas expressões de sentimento, então tudo aponta para uma solução: o paciente está num estado de alma no qual todas as suas impressões, ou suas lembranças delas, não estão mais mantidas juntas por uma cadeia associativa... (Freud, 1893/1975, p. 19-20)

Ou seja, trata-se de um estado em que a lembrança pode estar presente sem que o eu tome conhecimento dela ou possa intervir sobre ela. Como vemos, desde a época em que Freud formula essa diferença de estados já estão presentes todas as bases para a constituição do conceito de inconsciente, mesmo que o termo ou a noção ainda não houvessem sido estabelecidos. Trata-se de afetos que agem sobre o sujeito sem que ele tenha conhecimento deles e, no entanto, se nos aproximamos de sua história, encontramos algo que os justifica: o trauma. Ou seja, há uma quebra na cadeia associativa que não permite que os processos mentais entrem em contato com tais afetos, de forma que o paciente fica à mercê deles, sem ter ascendência sobre eles, sem poder dominá-los ou sequer entendê-los. Estamos, então, diante de algo que determina os estados subjetivos para além da consciência que o sujeito possa ter deles ou de seus efeitos. Está assim fertilizado o solo de onde nascerá a teorização freudiana que se desenvolverá no sentido de formular, mais tarde, o desejo inconsciente que habitará o sujeito psicanalítico.

Para a questão que nos interessa no presente trabalho, é necessário ressaltar que o método ou as técnicas de pesquisa nos quais Freud havia se formado e sobre os quais havia mostrado excelente habilidade de manejo não poderiam mais ser-lhe úteis. Trata-se agora de desenvolver os meios para lidar com um objeto, o inconsciente, que se apreende por seus efeitos de estranheza sobre o discurso do sujeito, discurso esse que se dá na e por causa da relação que mantém com o analista.

Além disso, há na questão do objeto, assim formulada, um ponto que a complexifica e introduz uma nova problemática. Se no caso das ciências médicas, por exemplo em uma investigação histológica como as conduzidas por Freud, tratava-se quase sempre de aplicar um método de investigação a um objeto já delimitado, o mesmo não se passa com o novo saber que surge. $\mathrm{O}$ inconsciente se constitui, se faz presente no ato mesmo da escuta do analista, no momento mesmo da presença do analista junto a quem fala. A 
especificidade é dada pelo fato de, ao se constituir, ao se elaborar o objeto, ao se dar a ele certa consistência e divisar-lhe o modo de operação, é nesse mesmo movimento que se concebe o método de pesquisá-lo. Trata-se de um objeto que só pode ser apreendido no campo da práxis analítica, tornando necessário um novo entendimento sobre a pesquisa nesse campo.

\section{Os procedimentos da pesquisa psicanalítica}

Tendo em vista a característica do objeto psicanalítico de se deixar circunscrever apenas em análise, decorre que o procedimento de pesquisa tem na clínica o seu ponto de apoio principal. É na referência ao material clínico que a pesquisa ganha seu colorido, sua vivacidade e, acima de tudo, sua originalidade em relação às pesquisas desenvolvidas em outros campos.

Nesse ponto, um fator importante contribui para que, decisivamente, a pesquisa psicanalítica se afirme em sua particularidade. Uma vez que a clínica desempenha um papel tão decisivo na pesquisa, o analista é aí objeto tanto quanto o analisante e as produções inconscientes que emergem na cena analítica. A conseqüência mais imediata é que o pesquisador não é apenas uma variável a ser controlada, pois fala de determinado lugar e, com sua fala, é causa do que emerge na sessão. Ele está implicado no material de uma forma na qual a neutralidade se torna impossível e indesejável, ou seja, o pesquisador está implicado de maneira indissociável do material que analisar.

A pesquisa nessa área é sempre nutrida pela clínica e, especialmente, pela singularidade de cada caso clínico. Este comporta todo o procedimento analítico e é inteiramente dependente da transferência (da relação analista-analisante), que permite a emergência do inconsciente. Por sua vez, a singularidade do caso clínico que se constituirá no material de análise, justamente por sua singularidade, passa a exigir constante atualização. Reencontramos aqui a mesma preocupação que tinha Charcot em seguir os casos clínicos e neles encontrar o novo, que podia mesmo contradizer o estabelecido teoricamente por outros autores (Freud, 1893/1975).

Por não se tratar de um procedimento empirista, contudo, não se pode atribuir exclusivamente ao contato com o discurso do paciente, com a clínica, a possibilidade da conceituação psicanalítica. Como Freud (1905/1996b) afirmou em relação a seu estudo sobre a sexualidade infantil, "se os homens pudessem ter aprendido com a observação direta das crianças, estes três ensaios poderiam não ter sido escritos" (p. 120). Com isso, chama a atenção para o fato de que, a par da observação ou do momento de análise, é preciso que o analista faça um trabalho que lhe permita formar um juízo, tanto quanto possível "não influenciado por suas aversões e seus preconceitos" (Freud, 1905/1996b, p. 120).

Não se trata, pois, da observação pela observação, de esperar de uma sessão analítica "o que vier", de estar diante do analisante como um leigo estaria. É preciso que o mergulho na clínica seja acompanhado da elaboração, do trabalho analítico sobre as questões que sustentam o contato com o paciente. Só assim pode-se valer do que emerge na clínica.

$\mathrm{O}$ que estamos considerando o trabalho do analista inclui o que vemos ser a preocupação de Freud com a busca de formulações teóricas mais claras e precisas. Ele argumenta que se toda ciência reclama para si a construção de conceitos básicos sobre os quais se erige, em nenhuma delas, nem mesmo nas mais exatas, parte-se de definições já prontas. "O começo correto da atividade científica", afirma,

\section{consiste antes em descrever fenômenos, que logo são agrupados, ordenados e inseridos em conexões. [...] já para a descrição mesma é inevitável aplicar ao material certas idéias abstratas que se recolben de alguma outra parte, não só da experiência nova. (Freud, 1915/1996b, p. 113)}

Freud (1932/1996) volta a insistir, em outra ocasião, que se trata "real e efetivamente de concepções, vale dizer, de introduzir as representações abstratas corretas, cuja aplicação à matéria bruta da observação faz nascer nela ordem e transparência" (p. 75; ver também Lacan, 1962-1963, Lição 7). Tal ordem e transparência, podemos dizer, permitirão às definições primeiro utilizadas um crescente refinamento. Em um movimento constante de ida e vinda da teoria para a realidade surgida na clínica, irão delimitando-se, circunscrevendo-se os conceitos que, articulados, aperfeiçoarão a teoria. Esta, por sua vez, dará conta melhor da realidade clínica, em um igual movimento de constante aprimoramento de um saber que, diga-se de passagem, se entende como inacabado e não totalizante.

A presença de toda a formação científica de Freud se faz notar na preocupação com a exatidão, com a não-contradição no conhecimento e na demonstração dos conceitos com os quais se pretende lidar. Por outro lado, é o próprio saber psicanalítico que confronta Freud $(1915 / 1996)$ com o reconhecimento de que "O progresso do conhecimento não tolera qualquer rigidez, tampouco nas definições" (p. 113). Há momentos em que é preciso recorrer à especulação, sem o apoio da qual, precário que seja, não seria possível continuar. É por meio dela, muitas vezes, que se cumpre a árdua tarefa de construir a parte que falta para orientar a observação e dela tirar as lições necessárias ao estabelecimento de uma teoria (Freud, 1937/1996, p. 228). 
O que vemos, nesse ponto, é o resultado de uma formação que valoriza o procedimento científico, poderíamos dizer, à outrance. Freud acredita no poder das investigações. É crendo nele que pode ir além da repetição que as amarras metodológicas lhe impõem. Assim, pôde dar lugar ao novo, escutá-lo na fala das histéricas e chegar ao inconsciente.

\section{Considerações finais: a pesquisa psicanalítica na atualidade}

Os argumentos desenvolvidos levam-nos a concluir que, na posição de pesquisadores em psicanálise nos dias atuais, colocamo-nos como herdeiros de um século de procedimentos investigativos que se seguiram aos de Freud. Se vemos a maneira como Freud opera e estabelece o saber psicanalítico, sabemos também que não nos encontramos nas mesmas condições que ele. Muito da teoria se estabeleceu nesse período, e ela é um dos pontos de apoio fundamentais com o qual contamos para dar continuidade à tarefa de manter a psicanálise.

Manter a psicanálise, é importante esclarecer, não é deixá-la empedernida e estática, mas sim, antes de tudo, manter o vigor que Freud soube lhe imprimir, o vigor que foi capaz de fundar um novo campo, inaugurar uma nova forma de pensar, levando em conta um objeto que não se faz presente a não ser por seus efeitos no discurso de um sujeito. Manter a psicanálise tampouco é fazê-la emular os procedimentos das ciências naturais, desconhecendo a especificidade de seu objeto.

Dessa forma, ao nos sabermos depositários da psicanálise que veio se fazendo ao longo do século XX, é importante que conheçamos sua história e a história de sua construção como disciplina, e que tenhamos contato com o legado de seus autores. Temos aí, inclusive, a justificativa para um dos procedimentos capitais, a ida aos textos que estabelecem os conceitos e as formulações teóricas. É por meio deles que recebemos as teorias refinadas ao longo desse período. A consulta aos trabalhos escritos, nesse momento, é crucial para que se reescreva dado conceito ou se acompanhem suas formulações com vistas a julgar sua pertinência ou sua mais rigorosa aproximação das questões, surgidas da clínica, com as quais o analista estará lidando. Esse procedimento de investigação que lida com a trama conceitual muitas vezes é confundido com toda a pesquisa psicanalítica; é quando a produção psicanalítica é tomada (não sem uma certa má-fé por parte daqueles que assim a consideram) por uma extensa revisão bibliográfica.

Trata-se, ao contrário, do trabalho da análise já em seu desenvolvimento. Trata-se de entrar em contato com a história das elaborações prévias já realizadas em psicanálise e de, justamente, não reconhecer nelas uma massa de informações prontas e definitivas. Não se trata, portanto, de fazer de seu objeto, cuja especificidade insistimos em demonstrar, algo passível de apreensão pelas técnicas e pelos métodos de pesquisa de outras áreas de saber. É importante que se possam fazer perguntas aos textos. Examiná-los para saber seu alcance quanto às questões que lhe são formuladas. É importante, ainda, o exame da construção dos conceitos e do lugar que ocupam em um arcabouço teórico: por que surgem, quais as démarches lógicas no desenvolvimento da teoria analítica que fazem com que se tornem necessários. É importante acompanhar, observar que o conceito não se constrói de forma arbitrária, mas surge no movimento de vai-e-vem dos textos às situações clínicas e delas de volta aos textos, e só se torna possível por referência à presença do analista diante do analisante.

É preciso restabelecer, reencontrar no procedimento da pesquisa analítica todo o rigor que Freud trouxe a ela, assim como manter viva a audácia de não se deixar apreender nas malhas de um conhecimento já mapeado. É necessário fazer valer sua descoberta de um cotidiano aparentemente simples e prosaico, feito de sonhos, lapsos, sustos e angústia. Cotidiano que não se deixa apreender, a não ser pela psicanálise dessas formações apresentadas pelo inconsciente, que nesse século provaram ser a matériaprima tanto da investigação psicanalítica quanto da realidade que constitui o sujeito.

\section{Referências}

Althusser, L. (1965). Pour lire le capital. Paris: Maspero.

Bachrach, H. M., Galatzer-Levy, R., Skolnikoff, A. Z. \& Waldron, S. Jr. (1991). On the efficacy of psychoanalysis. Journal of the American Psychoanalytic Association, 39, 871-916.

Beividas, W. (1999a). O excesso de transferência na pesquisa em psicanálise. Psicologia: Reflexão e Crítica, 12(3), 661-680.

Beividas, W. (1999b). Pesquisa e transferência em psicanálise: lugar sem excessos. Psicologia: Reflexão $e$ Crítica, 12(3), 789-796

Berchérie, P. (1983). Genèse des concepts freudiens. Paris: Navarin Editeur.

Birman, J. (1993). O objeto teórico da psicanálise e a pesquisa psicanalítica. Em J. Birman. Ensaios de Teoria Psicanalítica. (p. 13-24). Rio de Janeiro: Jorge Zahar.

Cremerius, J. (1999). The future of psychoanalysis. Em J. Cremerius (Org.). The future of psychoanalysis. (p. 338). London: Open Gate Press. 
Crews, F. (1986). Skeptical engagements. New York: Oxford University Press.

Crews, F. (1995). The memory wars. New York: New York Review of Books.

Dumont, F. (1994). Ritualistic evocation of antiquated paradigms. Professional Psychology; Research and practice, 25(3), 195-197.

Elia, L. (1999). A transferência na pesquisa em psicanálise: lugar ou excesso? Psicologia: Reflexão $e$ Crítica, 12(3), 775-788.

Ellenberger, H. F. (1970). The discovery of the unconscious: The bistory and evolution of dynamic psychiatry. New York: Basic Books.

Ellenberger, H. F. (1994). Histoire de la découverte de l'inconscient. Paris: Fayard.

Fonagy, P. \& Target, M. (1994). The efficacy of psychoanalysis for children with disruptive disorders. Journal of the American Academy of Child and Adolescent Psychiatry, 33, 45-55.

Fonagy, P. \& Target, M. (1996). Predictors of outcome in child psychoanalysis: a retrospective study of 763 cases at the Anna Freud Center. Journal of the American Psychoanalytic Association, 44(1), 27-77.

Freud, S. (1975). Charcot. Em J. Strachey (Org.). Standard Edition of the Complete Psychological Works of Sigmund Freud. Vol. III, p. 11-23. London: Hogarth Press.

Freud, S. (1987). Contribution à la conception des aphasies. Paris: PUF. (Original publicado em 1891).

Freud, S. (1996a). La interpretación de los sueños. Em Sigmund Freud Obras Completas. Vol. IV, p. 1-608. Buenos Aires: Amorrortu.

Freud, S. (1996b). Tres ensayos de teoría sexual. Em Sigmund Freud Obras Completas. Vol. VII, p. 109-222. Buenos Aires: Amorrortu.

Freud, S. (1996c). Pulsiones y destinos de pulsiones. Em Sigmund Freud Obras Completas. Vol. XIV, p. 105134. Buenos Aires: Amorrortu.

Freud, S. (1996d). Más allá del principio de placer. Em Sigmund Freud Obras Completas. Vol. XVIII, p. 1-62. Buenos Aires: Amorrortu.

Freud, S. (1996e). Nuevas conferencias de introducción al psicoanálisis. Conferencia $32^{\mathrm{a}}$. Em Sigmund Frend Obras Completas. Vol. XXII, p. 75-103. Buenos Aires: Amorrortu.

Freud, S. (1996f). Análisis terminable e interminable. Em Sigmund Freud Obras Completas. Vol. XXIII, p. 211-219. Buenos Aires: Amorrortu.
Garcia-Roza, L. A. (1993). A pesquisa acadêmica em psicanálise. Em D. Ropa (Org.). Anuário Brasileiro de Psicanálise. (p. 118-121). Rio de Janeiro: Relume-Dumará.

Gay, P. (1989). Freud, uma vida para o nosso tempo. São Paulo: Companhia das Letras.

Gedo, J. E. (2001). The enduring scientific thought of S. Freud. Em J. Winer \& J. Anderson (Org.). The annual of psychoanalysis Vol. XXIX - Sigmund Freud and his impact in the modern world. (p. 105-115). Hillsdale: Analytic Press Inc.

Gondar, J. (1995). A pesquisa em psicanálise. Cadernos do Tempo Psicanalitico, 1, 68-73.

Holt, R. R. (1985). The current status of psychoanalytic theory. Psychoanalytic Psychology, 2(4), 289-315.

Holt, R. R. (2002). Quantitative research on the primary process; method and findings. Journal of the American Psychoanalytic Association, 50(20), 457-482.

Irwin, J. (1996). Science or hermeneutics: Psychoanalysis in search of self definition. Modern Psychoanalysis, 21(1), 61-89.

Jones, E. (1980). Sigmund Freud, life and work. London: The Hogarth Press.

Kantrowitz, J. L., Katz, A. L., Greenman, D. A., Humphrey, M., Paolitto, F., Sashin, J. \& Solomon, L. (1989). The patient-analyst match and the outcome of psychoanalysis: A pilot study. Journal of the American Psychoanalytic Association, 37, 893-919.

Lacan, J. (1962-1963). L’Angoisse. Seminário Inédito.

Lacan, J. (1975). Le seminaire, livre I: Les écrits techniques de Frend. Paris: Seuil.

Laplanche, J. (1966). La Recherche Psychanalytique. Revue de L'Enseignement Supérieur, La Psychologie, 2, 146-153.

Laplanche, J. \& Pontalis, J.-B. (1967). Le vocabulaire de la psychanalyse. Paris: Seuil.

Légrand, M. (1973) Le statute scientifique de la psychanalyse. Topique, 11-12, 237-258.

Lino da Silva, M. E. (1993). Pensar em psicanálise. Em M. E. Lino da Silva (Org.). Investigação e psicanálise. (p. 11-25). Campinas: Papirus.

Machado Pinto, J. (1999). O sujeito da psicanálise: ciência e crença. Ágora - Estudos em Teoria Psicanalítica, 2(2), 9-14.

Magnavita, J. L. (1993). The evolution of short-term dynamic psychotehrapy: Treatment of the future? Professional Psychology: Research and Practice, 24, 360-365.

Mezan, R. (1990). Metapsicologia/Fantasia. Em J. Birman (Org.). Freud: 50 anos depois. (p. 115-132). Rio de Janeiro: Relume-Dumará. 
Mezan, R. (1993). Que significa "pesquisa” em psicanálise? Em M. E. Lino da Silva (Org.). Investigação e psicanálise. (p. 49-90). Campinas: Papirus.

Nash, M. (1990). The debate over Freud's selfunderstanding. Psychoanalytic Review, 77(3), p. 341-350.

Nobre, L. (1999). Sobre o ato de pesquisar em psicanálise: algumas considerações. Agora - Estudos em Teoria Psicanalítica, 2(2), p. 37-42.

Oremland, J. D., Blacker, K. H. \& Norman, H. F. (1975). Incompleteness in "successful" Psychoanalysis: A follow-up study. Journal of the American Psychoanalytic Association, 23, p. 819-844.

Palombini, A. L. (1999). Fundamentos para uma crítica da epistemologia da psicanálise, Ágora - Estudos em Teoria Psicanalitica, 2(2), 53-70.

Popper, K. (1968). The logic of scientific discovery. New York: Hutchinson.

Psychoanalytic Psychology. (1989). Editor's note. Psychoanalytic Psychology, 6(3), 375.

Safra, G. (1993). O uso de material clínico na pesquisa psicanalítica. Em M. E. Lino da Silva (Org.). Investigação e psicanálise. (p. 119-132). Campinas: Papirus.

Safran, J. D. \& Aron, L. (2001). Introduction: Symposium on implications of the empirically supported treatment controversy for psychoanalysis, Psychoanalytic Dialogues, 11(4), 571-582.

Schachter, J. (2002). Transference: Shibboleth or albatross? Hillsdale: Analytic Press, Inc.

Shevrin, H. (1995a). Is psychoanalysis one science, two sciences or no science at all? A discourse among friendly antagonists. Journal of the American Psychoanalytic Association, 43(4), 963-986.

Shevrin, H. (1995b). Is psychoanalysis one science, two sciences or no science at all? A discourse among friendly antagonists: Commentary reply. Journal of the Amerbcan Psychoanalytic Association, 43(4), 1035-1049.

Strachey, J. (1975). Editor's introduction. The standard edition of the complete psychological works of Sigmund Freud. Vol. IV, p. xi-xxii. London: Hogarth Press.

Strupp, H. H., Schacht, T. E. \& Henry, W. P. (1988). Problem-treatment-outcome congruence: a principle whose time has come. Em H. Dahl, H. Kachele \& H. Thoma (Eds.). Psychoanalytic Process Research Strategies. (p. 1-14.). New York/Berlin: Springer Verlag.

Target, M. \& Fonagy, P. (1994a). The efficacy of psychoanalysis for children with emotional disorders. Journal of the American Academy of Child and Adolescent Psychiatry, 33, 361-371.

Target, M. \& Fonagy, P. (1994b). The efficacy of psychoanalysis for children: Prediction of outcome in a developmental context. Journal of the American Academy of Child and Adolescent Psychiatry, 33, 1134-1144.

Wallerstein, R. S. (2001). The generations of psychoterapy research: An overview. Psychoanalytic Psychology, 18(2), 243-267.

Wallerstein, R. S. (2003). Psychoanalytic therapy research: Its coming of age. Psychoanalytic Inquiry, 23(2), 375-404.

Weber, J. J., Bachrach, H. M. \& Solomon, M. (1985a). Factors associated with the outcome of Psychoanalysis: Report of the Columbia Psychoanalytic Research Center Project. (II) International Review of Psychoanalysis, 12, 127-141.

Weber, J. J., Bachrach, H. M. \& Solomon, M. (1985b). Factors associated with the outcome of Psychoanalysis: Report of the Columbia Psychoanalytic Research Center Project. (III) International Review of Psychoanalysis, 12, 251-262.

Weber, M. (1949). Objectivity in social sciences and social policy. Em M. Weber. The Methodology of Social Sciences. (p. 11-123). New York: The Free Press.

Recebido em novembro de 2002 Reformulado em novembro de 2003 Aprovado em dezembro de 2003

Sobre a autora:

Anna Carolina Lo Bianco é psicóloga formada pela PUC-Rio, mestre em Psicologia Clínica e doutora em Sociologia da Saúde Mental pela Universidade de Londres. É professora do Programa de Pós-Graduação em Teoria Psicanalítica, do Instituto de Psicologia da UFRJ e pesquisadora com bolsa de produtividade em pesquisa do CNPq. 
